\title{
"Monkey See, Monkey Do, That's Not Going to Actually Teach You": Becoming a Self- Directed Learner in Enabling Mathematics Units
}

\author{
Gemma Mann \\ CQUniversity, Australia \\ Julie Willans \\ CQUniversity, Australia
}

\begin{abstract}
To explore the mathematics learning experiences of those more likely to come from non-traditional educational backgrounds, ten students studying one or two maths units in the Skills for Tertiary Education Preparatory Studies (STEPS) at CQUniversity Australia were interviewed. The aim was to investigate how these students learnt to become self-directed learners during their preparation for their intended undergraduate study. Using grounded theory methodology, data were analysed within the theoretical framework of andragogy, namely, adult learning. Analysis of data indicated that students were able to learn how to become self-directed learners when lecturers 'tailored' teaching to the students' needs, taking into consideration their state of mind, ability to plan their work, developing adeptness at engaging in mathematical activities, and assistance received in evaluating their own learning outcomes. In practice, findings of this study provide some insight into how enabling mathematics lecturers can tailor activities to best meet the needs of their students. Further, the development of self-directed learning skills in the context of mathematics has potential to benefit these students in all their university study.
\end{abstract}

Keywords: Enabling education; mathematics; self-directed learners; STEPS

\section{Overview}

This article draws from a Master of Education study and seeks to focus on andragogical practices that a small group of students enrolled in one of two mathematics units in an enabling course identified as having enhanced their capacity for self-directed learning. An important goal for mathematics' lecturers in any enabling context is development of students' self-directed learning skills. However, this can be problematic for those students whose prior learning in mathematics has been disrupted or negatively impacted. For some students, this has resulted in "mathematics anxiety" and they may have difficulties engaging with mathematics learning and truly embracing self-directed learning. In enabling contexts, maths lecturers are generally very mindful of the often-negative mathematics experiences of their students and thus focus on helping them to develop the right mind set to plan their own study, do their own learning, and evaluate how their learning is going. This article first sets the context for the study, namely the Skills for Tertiary Education Preparatory Studies (STEPS) course at CQUniversity Australia. It is based on interview findings with ten students enrolled in either Fundamental Maths for University (FMU) and/or Intermediate Mathematics for University (IMU). Next, the article explains how principles of grounded theory methodology (Charmaz, 2014) informed the data gathering phases and early analysis, and then uses andragogy as described by Knowles

This work is licensed under a Creative Commons Attribution 4.0 International Licence. As an open access journal, articles are free to use with proper attribution. ISSN: 2205-0795 
(Knowles 1981; Knowles et al., 2005) as a theoretical framework to further analyse the data. The analysis is framed by the adult learning constructs of: state of mind; planning; doing; and evaluating. It was found that the notion of 'tailoring' emerged as an important precursor for self-directed learning, prompting a discussion of the implications for teaching mathematics in STEPS. The article concludes with some suggestions for application of findings to other higher education contexts and the suggestion of future possible research.

\section{Context}

The comprehensive model of offerings currently in place at CQUniversity offers all levels of courses (programs) from Certificate I to PhD. In line with the Academic Qualifications Framework [AQF] (2013), these courses offer multiple pathways for students considering a tertiary level or post-school education. To determine a student's eligibility, these centres assess school grades, including OP (overall position) or ATAR (Australian Tertiary Admission Rank), other qualifications or coursework including certificates and diplomas, and work experience. It has been found that many students are entering university with considerably low mathematics ability (Duffy \& Wylie, 2019; Thomson et al., 2017). For a variety of reasons, more and more students are without the necessary formal schooling qualifications for direct entry to degree courses. For example, they have not gained adequate passing grades; they have gaps in certain areas, such as numeracy; they opted not to aim for an OP at secondary school; or they withdrew from school. One option to gain direct entry to a Bachelor degree (AQF level 7) is to successfully complete an enabling course (Pitman \& Trinidad, 2016), specifically designed to facilitate entry to tertiary level education at the undergraduate level. Enabling courses are sometimes called bridging/access courses or alternative pathways, and in Australia, they are designed to provide prerequisite levels for entry at the AQF 7 level yet are designated as 'non-award' as they are not mapped to an AQF level. One such enabling course is STEPS at CQUniversity Australia.

Operating since 1986, STEPS is specifically designed to introduce students to the university environment in a manner that involves familiarising them with the processes and procedures (culture) and terminology (language), along with discipline knowledge (Pitman \& Trinidad, 2016). As such, STEPS aims to provide context and content specific learning and offers a lowcost pathway to bachelor level courses, where "characteristically, applicants wish to access higher education but find they lack the essential knowledge and skills to successfully gain entry to a tertiary institution" (Seary \& Willans, 2004, p. 310). Seary and Willans (2004) also cite findings that many STEPS applicants are "unable to or unsuccessful in completing the essential prerequisites to enter a tertiary institution [because they] have been hindered by both their past and present educational, social or cultural situations and most have serious misgivings about their academic ability and chance at success" (p. 310). However, these authors found that most students "seek to improve their quality of life through firstly improving their educational standing by undertaking a preparatory program ...” (p. 310). This is supported by more current findings of researchers in enabling education at the University of Newcastle, such as Bunn and Westrenius (2017) who also found that students aim to increase their education and gain the required skills for university, but also to "fulfil psychological and social needs" (p. 61).

STEPS is a flexible course, with up to eleven units available for completion within a two-year time frame. Students are required to complete the core unit, Preparation Skills for University (PSU), plus a minimum of at least two other units. Each student's overall study plan is developed during a personalised interview with an Access Coordinator (AC) who considers the undergraduate course the student is aiming to enter, and any prior studies undertaken. There is an AC for each campus ${ }^{1}$ where STEPS is offered, and one for students studying by online education. One role of the AC is to discuss the requirements of the undergraduate course a student is hoping to enter and align these with the required units in STEPS. Each undergraduate course at CQUniversity has a set of STEPS units as prerequisites, decided upon by the STEPS Head of Course in collaboration with the undergraduate Heads of Course, and recommended or elective units negotiated between the AC and the student ${ }^{2}$. Due to the structure of degrees courses at CQUniversity (CQUniversity, 2018), there is a range of units that include mathematical concepts, and these units sit across a range of courses ${ }^{3}$. In cognisance of research and reports that show the worrying status of mathematical proficiency of prospective university students, and conscious of past experiences of student performance, many Heads of Course at CQUniversity have requested that recommended study plans for STEPS students hoping to articulate to those courses with maths units include at least one mathematics unit to complement existing student knowledge.

\footnotetext{
${ }^{1}$ CQUniversity is a multi-campus university with STEPS being offered on-campus at ten campuses and also by Online Education (OE). Each of these campuses and OE has an Access Coordinator.

${ }^{2}$ Prerequisite recommended and elective units through STEPS are only for students applying for entry to undergraduate courses through the STEPS enabling course.

${ }^{3}$ At CQUniversity, a 'unit' is a single subject, and a 'course' is a bachelor's degree, diploma or certificate made up of several units.
} 


\section{STEPS History and Use of Self-Directed Learning Principles}

STEPS aims to develop a key aspect of students' abilities, namely, to be self-directed learners. One of the guiding principles of STEPS is informed by the beliefs of Malcolm Knowles and his conception of adult learning (Seary \& Willans, 2004). STEPS recognises that students bring with them a prior self-concept and actively build on this through "encouragement and celebration of self-directed and autonomous learners" (Seary \& Willans, 2004, p. 313). A central aspect of STEPS is therefore to help students gain the ability to competently self-manage their study. This is a competency that many commencing STEPS students may have little experience of, and therefore must learn and master, along with any specific subject-based content. Preparatory Skills for University (PSU), a compulsory unit in STEPS, is studied in the first term of a student's STEPS enrolment. This core unit aims to create self-directed learners through topics such as active reading and listening (note-taking, note-making and paraphrasing), research skills (finding, evaluating and citing scholarly information), oral presentation skills, career planning, stress management and resilience, assessment strategies, and critical thinking skills. Students read, discuss, act upon and reflect on these topics with the aim of "developing strong study habits and effective learning strategies; negotiating procedures and systems used at university; and developing communication skills appropriate for higher education" (Holden, 2018, p. 5). According to Holden (2018), PSU "is designed to help students become self-directed, active and confident learners ... [including] time management and goal-setting; individual study" (p.1). The unit has additional topics such as practical tips for effective learning, the exploration of learning styles preferences and personality types, and the investigation of careers options. Teaching practices in PSU are designed to meet learning outcomes for each student, with a focus on becoming "a confident and self-directed learner; [who can] apply critical thinking skills in a range of contexts, with a particular focus on critical selfreflection; [and is able to] set and manage goals for individual study" (Holden, 2018, p. 5).

The above-mentioned skills are required for FMU and IMU as a foundation for Bachelor courses across many disciplines. FMU is often the first time many students have formally engaged with mathematics since school. It begins at about a primary grade four level with addition, subtraction, multiplication and division, and works through to about a secondary grade nine to ten level with algebraic equations and exponents. IMU aims to give students a sound mathematical knowledge approximately equivalent of a senior general mathematics level, with more complex algebra, geometry, trigonometry, and statistics.

It seems that many students coming into STEPS do so with the aim to build their learning capabilities, and then subsequently transfer these skills across disciplines to develop resilience and cope with the increasing difficulty of unit content they are required to study (Seary \& Willans, 2004). In mathematics, this process is not straight forward. Despite the foundational level content in FMU, empirical and anecdotal evidence over three decades of teaching in STEPS shows that students who enrol in STEPS with low levels of proficiency often have prior, negative experiences of failure from schooling which can be disadvantageous to this skills development (Seary \& Willans, 2004; Willans \& Seary, 2007). If they face obstacles in STEPS units that they are ill-equipped to deal with, they may revert to negative thought patterns about themselves as learners. This can, in turn, result in retreating to previously learned behaviours of withdrawal to save themselves the pain of yet another failure. Anecdotally, mathematics lecturers in STEPS have stated that some students have difficulty overcoming prior negative thoughts in this discipline and that this can impact their capacity for self-directed learning.

\section{Research Design}

To investigate the research question about what STEPS students say helps them develop their self-directed learning capabilities in mathematics, this study utilised an in-depth exploration of interviews with a small group of STEPS students who were enrolled in or who had completed either Fundamental Maths for University (FMU) or Intermediate Mathematics for University (IMU), or both. Employing Constructivist grounded theory methodology (GTM) as outlined by Charmaz (2014), the common data generation process of conducting semi-structured, individual interviews was undertaken with 10 students. GTM does not use a statistical sample and is not required to meet a certain demographic criterion (Morse, 2010), thus the participants in the study were students who had first-hand experiences in FMU or IMU or both, having lived the particular experience required for the study, and their recruitment was inherently targeted and non-random. Most of these students had studied on campus, but some had studied online. Ages ranged from late teens to late fifties with a mix of males and females. The participants chose their own pseudonyms (shown in brackets after quotes). Once interviews were recorded and transcribed, the qualitative framework of andragogy was used to sort the data into descriptive and theoretical categories. This framework is presented below. It is followed by the overall findings, and the analysis of these findings with respect to each category. 


\section{Theoretical Framework - Andragogy}

Knowles and colleagues (Knowles, 1981; Knowles et al., 2005) describe the theory of andragogy, or adult learning as distinguished from the learning done by children (pedagogy). It is premised on the notion that the learner is recognised as situated within the learning process and brings life experiences to the learning environment. Adult learners, therefore, seek to be involved in constructing their learning pathway and use previous and current experiences, along with future aspirations, to influence the direction of this pathway. Candy (1991) describes this as 'self-directed learning'. Andragogy, and the belief that adults can undertake study permeate most enabling courses, and key features of student-directed learning are relevant to adult learners in STEPS classroom. Knowles et al. (2005) describe eight elements of andragogy (p. 116) that are categorised into four general areas: state of mind, planning, doing, and evaluating. These four categories frame what it means to be an "adult" in the context of learning, when it is recognised as such from both the student's and the educator's viewpoint. In a university context, this is when a student: is mindful of and asserts control over their own thoughts; can understand what is required to plan their learning; has a metacognitive understanding of their actions while engaged in their study; and has the knowledge and tools to evaluate and revise their study habits and plans. These are described here.

\section{State of Mind}

The students' state of mind and openness to learning is critical for them to be able to benefit from focused teaching provided by the lecturer. Students must be prepared to learn, and this is something they may not have practised for some time. It is, however, an area where lecturers can help by preparing students for what they are likely to encounter within the formal learning environment. Importantly, the learning environment must be one is which the student feels relaxed and trusting, with acknowledgment shown by lecturers regarding the "psychological climate" of the learning environment (Tough \& Knowles, 1985, p. 708). This acknowledges that adult learners are generally aware of their mindset and use available information to alter or change it, are open and willing to learn, and can even find pleasure in learning. If students understand the content and are comfortable with a mindset that is open to input from lecturers, plus put their mind to learning, then there is a greater propensity for willingness and active participation in the learning process. This empowers their learning, and once they comprehend what they are trying to achieve, they can be more motivated to undertake what they are required to do. Candy (1991) explains that motivation is key to the learning of content that may otherwise not interest the learners, urging attention be paid to the "method of instruction, as distinct from the content of instruction" (p. 66). This can alert the learner to the relevance and importance of certain pedagogical activities, and in the context of maths education, enable them to see how activities related to individual abilities to understand and apply mathematical concepts are important, not just in the present, but as a competency to take into the future.

With the right motivation, students can be helped to overcome maths anxiety, a phenomenon well researched in the field. Maths anxiety has been attributed to a variety of causes such as lack of student uptake of mathematics subjects in high schools (Frith, 2011; McNeilage, 2014), a lack of high school teachers with sufficient knowledge and confidence in mathematics (Mather, 2014) or in how to teach for understanding (Heng \& Sudarshan, 2013), and the perpetuation of mathematics-related anxiety as it is passed on from teachers to students (Hughes-Warrington, 2013). Mathematics anxiety is a problematic state of mind, right from early primary school, and it can affect how children perform and how much mathematics they learn. Furthermore, this anxiety can continue from year to year (Vukovic et al., 2013), and once students reach high school, mathematics anxiety influences how well they perform (Yaratan \& Kasapoğlu, 2012). If students go on to university, mathematics anxiety has been shown to have strong links to grades in the subject (Kargar et al., 2010; Núñez-Peña et al., 2013). Finally, mathematics anxiety is strongly linked to previous poor performance, although poor performance due to high levels of anxiety is not necessarily a reflection of actual ability (Hoffman, 2010; Jansen et al., 2013).

\section{Planning}

Once students understand their ability to take more control of their mindset, they can become more involved in planning their learning by collaborating with their lecturers and other advisors. According to Candy (1991), it is important to empower students to plan their own study within any learning environment. Whereas in traditional classrooms, it is the teacher that formulates the learning activities, in adult learning environments students will have a more vested interest in their learning if they feel more in control of what and when they will study. This vested interest is discussed by Pintrich (1999) in his work 
involving motivation and education theories, which show that planning is a significant factor in self-regulated learning. He states that active planning was "strongly related to academic performance" (Pintrich, 1999, p. 465).

Knowles et al. (2005) assert that planning must be a collaboration between the lecturer and the student and involve diagnosing the student's learning needs, formulating learning objectives around those needs, and creating teaching plans to address those needs. If this is successful, students will likely be more able to articulate their individual needs to their lecturers. Students may then be more confident and specific in asking for help and be more receptive to input from their lecturers. This then links the planning stage to the doing stage as students are confident in what activities will help them learn.

\section{Doing}

A key point in andragogy concerns the definition of the learner 'doing'. This is particularly important in academic units such as mathematics, where the student must transition from hearing and seeing, to 'putting it into practise'. However, it is important to point out the difference between self-directed learning and self-teaching (Miflin, 2004). While Knowles et al. (2005) contend that adult students must be ready to learn and engage in the learning, it is vital that lecturers do not go to the opposite extreme and offer no help at all. As pointed out by Tough (1967), whose research also focused on adult, self-directed learning, it is uncommon for adults to be able to solely self-teach. Tough's research with 40 adults from various professional backgrounds choosing to undertake non-work related, self-determined learning projects found that even when the decision to undertake study was entirely the students' own, students "sought and obtained a very large amount of assistance" (p. 47). This assistance included a significant amount of help from the teacher with "deciding [which] activities" would be helpful and "dealing with difficult parts" (p. 48), thus indicating that informative, direct instruction on what to do and how to do it was necessary. The important point that Tough makes, however, is that adult learners must desire help for it to be effective. Furthermore, adult learners need the motivation to pursue study themselves, and then decide when to access help. In the adult learning environment, this ranges from deciding when to attend classes or online workshops, what content matter to pay attention to, and which learning activities to participate in.

Tough (1979) reiterates the vital role of decision-making by emphasising the importance of who is in control of the learning in adult learning classrooms. He notes that if students maintain control, but receive instruction, including direct teaching, they are more likely to request help, ask for further learning activities, decide from options offered by the teacher, and determine 'what' they will do 'when'. Significantly influencing this is their mindset and how much control they perceive themselves to have over their learning plan. If, however, the teacher is in control, it is up to the student as to whether to accept the dependent position. This is often witnessed in traditional classrooms where the teacher is the 'expert' and the student is the 'novice', namely, "teacher-directed education, wherein the learner has only the submissive role of following a teacher's instructions" (Knowles et al., 2005, p. 62). Such a teaching practice is contradictory to the mindset of learning from an andragogical perspective, where the students must be willing to develop control of their own mindset and participation in activities. Indeed, Tough argues that when teachers want to provide too much help, that is, "more help than desired ... [it] is often the sign of a helper who tried to control and dominate the learner's decisions and arrangements", consequently making the "learner feel that he (sic) had to resist the helper's attempts to influence his (sic) strategy and subject matter" (p. 192).

\section{Evaluating}

Knowles et al. (2005) emphasise that adult learners should be involved in evaluating their own learning. This entails encouraging students to reflect on their ability, and to continually work on increasing their proficiency to gain the ability to transfer their learning capabilities to any situation in the future. Adult learners are not only able to reflect on their learning of mathematics subject matter but also to evaluate their own abilities to learn. Again, Knowles et al. (2005) state that this is a collaborative effort between learner and teacher and hence reinforces the way that teaching is inseparable from the student learning experience.

\section{Findings}

The theoretical category of 'tailoring' was found to emerge from the data analysis. This category indicated the nature of the influence of others insofar as the influence was 'suited' to fit the needs of the student. In mathematics, in particular, there are so many times students need to grasp new concepts, lesson by lesson, even minute by minute, that lecturers need a way to deal 
with the differing levels of each student. It emerged from the data that tailoring to each student was important for their engagement and success. Using the four elements of andragogy enables the tailoring to be a manageable task for the lecturer, as it shares the responsibility for tailoring the learning with the students themselves.

Tailoring as discussed by the students in this study was analysed within the theoretical framework of andragogy. This facilitated an examination of how data supported the use of elements of andragogy in helping students become self-directed learners within the discipline of mathematics. The following section presents the student interview data in the four andragogical categories, and discusses how tailoring can be used within each one to make the most of the learning experience for each student.

\section{Teaching Mathematics for Self-Directed Learning Using Andragogy}

\section{State of Mind}

Interview data suggested that some students were aware of their own state of mind regarding mathematics upon entry to STEPS. Michelle and Cyndel recognised their prior strengths: "Percentages I thought I'd be good [at] and I was good at that" (Michelle); "sin, cos and tan, I remembered as well... I was really good at it" (Cyndel). Others, such as Caroline, identified development of a strength through the unit: "I actually got that good at doing it" (Caroline). On the other hand, Jane acknowledged she had a couple of areas of weakness: "I was never strong at it at school; I'm particularly bad at still... positives and negatives" (Jane). In terms of being in the right frame of learning, the data also highlighted that students said it was easier if teaching and learning had relevance to their everyday life. Charlie commented that STEPS lecturers helped him relate the maths content to the real world as he often struggled with that: "Like I did a question today and I looked at [lecturer], where am I going to use that in the real world? Like help me here" (Charlie). Jane and Thomas suggested ways that lecturers could explain more relevance of teaching activities which would benefit student learning. In referring to real life situations, Jane said: "If you give that problem to me in words, in more a real life situation then I can figure it out" (Jane). Similarly, Thomas talked about the benefit of more realistic problem-solving activities:

I feel like, maybe using more specific examples, especially with the application problems. Like, right now, doing trigonometry, it's like someone standing at a cliff looking down, well, I feel like there would be some real world application that you could write... they're at the airport and something to do with the radar and it's looking up at a plane... it's a bit monotonous, somebody standing on a cliff looking down at a boat. Why is he looking at the boat? (Thomas)

Jane indicated that mathematical problems do not necessarily have to be directly related to something students do, such as work or a hobby, providing they are close enough and real-world enough for her to see that mathematics does have relevance beyond the classroom. As she said: "The examples will give you a real-life scenario and you go, oh yeah ... It may not exactly apply to you, but something similar you know, you can make it fit" (Jane). Stevie also highlighted that mathematics problems involving "drug calculations, obviously all that stuff" (Stevie) would be relevant to several health-related courses such as Nursing and Paramedic Science. When asked: "Does it help when [STEPS lecturers] link maths to real world concepts?" (interviewer), Mike agreed that it might help people who struggle with maths, saying: "for me personally, I don't think it would make too much of a difference just because of my own affinity with maths. For others I think it would really provide a benefit" (Mike). The above students benefitted from the lecturer tailoring the mathematics to reflect the real world, demonstrating that a wide variety of examples that match the students' past experiences, current endeavours and future pathways can be useful in assisting students in learning maths.

Teaching approaches also had an effect on maths anxiety, one of the major barriers impacting a student's positive mindset. As adults can learn to change their mindset with positive input from the lecturers, teaching approaches can be pivotal to success in overcoming maths anxiety. One key way lecturers impacted the engagement level for Jane and Cathy was through appropriate and meaningful teaching approaches. Jane liked that the "[lecturer] is a complete professional and she... the way she teaches, and the way she approaches people I think is really well rounded" (Jane). Cathy appreciated the lecturer's enthusiasm, saying that:

I found Fundamental maths really easy to follow... it was full on, but it seemed to be enjoyable. I don't know whether it was the teacher maybe that made it more interesting ... she was just bubbly and made it sound exciting ... because she got excited about it (Cathy). 
Jane and Cathy found that the way the lecturers taught the content made them feel more comfortable in the class and therefore more receptive to learning.

\title{
Planning
}

With help from lecturers, students can be informed about what they need to do to learn, and plan their study accordingly. They then have the capacity to determine the right amount of support and collaborate with lecturers who can help by tailoring learning activities to cater for individual needs. Kay divulged that: "having a teacher that's dedicated to the way that other people learn definitely helped me" (Kay). Thomas and Kasey commented that it was beneficial for the lecturer to take adequate time to step through the work as they required. Thomas commented on the individual support shown to him:

I've got to have somebody show me how to do a problem in person and talk me through it step by step the first time and the second and the third time maybe sometimes ... In class, on the white board ... I can't read through notes in silence and understand complicated problems (Thomas).

Kasey said that extra time given by the lecturer helped her and her classmates with concepts they struggled with:

\begin{abstract}
I think it's actually quite good ... he does take time. If you don't understand it ... he'll set times away and he'll help you see it in a hundred different ways ... And being able to have somebody that takes the time, you know, it's not just rushing everything through ... It's getting everybody to understand on the same level, then, well, you know, obviously you have to push for time and you've got so many things that you have to learn per week, but being able to allocate extra time and even if it's not in that week, if it's, you know, weeks after, and you're still struggling with that. (Kasey)
\end{abstract}

Thomas also highly regarded the interaction and conversation provided by a lecturer during class: "It's the back and forth that you can have with a teacher... You can ask the questions and you can almost criticise their way of doing it, and it makes you think about better ways to do it... and you feel more involved" (Thomas). The lecturer taking the time and providing support tailored to meet the student's individual needs was valued by Thomas and Kasey in terms of overcoming their struggles to learn the content.

\section{Doing}

The stage after planning is 'doing' in which it is the students who are 'doing'. As Knowles et al. (2005) explain, there are "principles of action that are likely to achieve desired changes in the learner" (p. 129), and so, to achieve a change, students must take an active role in their learning. The students in this study described this happening. Charlie mentioned the leap from seeing to doing, from the familiar to the unfamiliar, and from short term memory to long term memory. Practising helped him go from watching someone else demonstrate the work to actually being able to do it himself:

It's great to be able to look up there and copy what somebody's done. But that's not going to actually teach you. That doesn't actually teach me how to do something. I need to then implicate (sic) it myself and then have practise and then... to be able to duplicate it in my own head (Charlie).

Jane also described the problem of: "monkey see, monkey do where there was a lot of copying but maybe not as much comprehension on my behalf" (Jane) where she "just copied down what was on the board" (Jane). This resulted in her only being able to do problems on her own "if it looked similar" (Jane), whereas "if it was a little bit more advanced... I'm not sure" (Jane). Both Charlie and Jane acknowledge 'doing' as a vital step in understanding.

With tailoring from the lecturer, students can learn to become self-directed and develop their own self-help and problem-solving strategies. This was found in two ways: lecturers tailoring explanations of content in ways that encouraged students to construct their own understanding in their own terms; and giving students time and space to consolidate that understanding on their own. These approaches are described by Mike, Kasey, Cyndel and Jane, who appreciated when lecturers catered to the individual learning styles and preferences of students, had the knowledge and ability to explain concepts in alternative ways, committed the time and had the patience to explain several ways, encouraging them to try different ways themselves to construct their own understanding. Mike specifically mentioned his lecturer encouraging this exploration: 
My [lecturer] will write down as many methods as she can think of and then if another student has another method she'll go and write it up on the board so whatever method works and she's really, really encouraging of that" (Mike).

Kasey expressed her appreciation for when the lecturer understood her learning styles and prior learning history:

You know, having that different thought process ... he understood how my brain ticked and was able to teach me along that line and I've been able to click everything since ... he was able to actually manipulate, or not manipulate, you know it's understanding the way that you think and being able to teach to that that way (Kasey).

Cyndel also appreciated the lecturer knowing her learning style and how this helped with maths learning: "I find she explains it a lot more. Maybe she knows the way I take it in" (Cyndel). Jane found her lecturer to be very flexible with catering to diversity:

She has been excellent with people who are obviously really advanced with their maths skills and she will be able to talk to them ... at that advanced maths level, but in the same breath she's answering a question over here which is at really, really basic level and there's no difference in her and I think that makes a really big impact for me (Jane).

Tailoring by the lecturer in the classroom helped these four students understand and "take it in", and thus their learning was more effective.

Most students in this study were cognisant of what the lecturers did to tailor their teaching and judging when to give, or when to hold back explicit instruction. Kay mentioned the lecturers encouraged her to try the problems on her own: "[lecturer] just told me it was ok to be flustered and frustrated" (Kay). It was found that the transition from direct instruction to independent work allowed Jane to become an independent learner and find her own ways to overcome issues: "Little frustrations yeh, but nothing that I haven't been able to work out at home ... by going over everything again" (Jane). When Cyndel became 'stuck', however, she appreciated tailored facilitation and prompting from the lecturer:

There was one ... that I did over the last couple of days, I just asked [the lecturer] after today's lecture. And yeah, he showed me how it was done. I could work out some, but that one line ... I couldn't get it (Cyndel).

She again mentioned later in the conversation that tailoring helped her through a struggle:

[the lecturer has] done really well, like I've been happy with the way he's been teaching and he saw that I got stuck with logarithms and functions and he like gave me that little bit of extra tutoring that I needed to get through it (Cyndel).

Kay also appreciated that the lecturer would tailor the explanation if needed as a safety net: "and then I just took a couple of deep breaths and she explained it a bit more or I asked her questions" (Kay).

In enabling mathematics units, the students' resolve to succeed is often low due to ineffective previous learning and negative classroom experiences. This puts increasing pressure on STEPS lecturers to provide a tailored experience. As Tough (1979) found, if the teaching is "congruent with the amount of help that the learner wanted or welcomed" (p. 192), it meant that students were not put in situations that induced anxiety. By creating an environment where students maintain control of their own learning, anxiety can be decreased. When the students acknowledge that they are responsible for engaging with learning, they are more willing to be open to assistance, even to the point of receiving direct instruction.

\section{Evaluating}

Students in this study commented on different ways they were able to evaluate their learning experiences. Firstly, they reflected on differences between their previous maths experiences compared to current experiences, and secondly, they had evaluated and come to appreciate their own learning style preferences. Mike and Thomas indicated that they were now enjoying their maths unit: "I think that is just a fact of life. If you are interested in something, you're paying attention so then you remember it" (Mike); "it's easier for me to understand maths when I'm interested in it; I wasn't nearly as mature when I was in high school... and ... I probably have a deeper appreciation for its role in the world, now than I did" (Thomas). Stevie also reflected on how a previous teacher had had a negative emotional effect on her by not tailoring to her needs: "I had a really terrible grade 4 teacher, like he was really mean to me especially with maths too, so I'm thinking ... well that following year that's every 
time I had maths I cried" (Stevie). She was then able to evaluate the STEPS experience as being different from school. When referring to STEPS maths, she said she was "looking forward to graphs and linears (sic) and stuff like that. I think that will be fun" (Stevie).

When students came to identify their learning style preferences and ways of meaning-making, it was clear they had evaluated their own individual learning strategies. Jane reflected: "I probably get more ... if there's things that I'm not too sure of, I probably get more out of coming home and watching the [lecturer's] clips which are fantastic... than I do out of sitting in a classroom" (Jane). Cathy had identified her best study time, sharing that: "I find if I do it, in the afternoons or before I go to bed, and then I sleep on it, it plays in my head all night and sometimes that helps" (Cathy). Thomas talked about the desire to commit learning to long term memory: "I actually want to remember what I learn and not just forget it straight after the test" (Thomas)

\section{Discussion}

In summary, Knowles' (1981; Knowles et al., 2005) elements of andragogy promote a student's ability to become more proficient learners in enabling education. Comments from students in this study highlight those aspects of student-lecturer interaction that can have a positive impact on their mathematics learning. The students have demonstrated that they can learn to be self-directed in their motivation to study and may also ask for help when needed. This provides lecturers with the ability to tailor a learning environment that actively promotes negotiation of learning plans and learning activities that are of most benefit for each student, assisting them in evaluating their progress. Findings in this study show that students enter STEPS mathematics units with a predetermined mindset, both around the decision to study, and due to their past experiences with mathematics. Understanding this mindset and tailoring teaching approaches accordingly meets the students where they are at and can positively influence and change the students' mindsets about mathematics. Continuing from this positive mindset, if teachers engage students in 'mutual planning' and 'mutual negotiation', students can play an active role and develop a vested interest in their learning. This varies considerably from other pedagogical techniques where the teacher alone is responsible for planning, and the person who "decides in advance what knowledge or skill needs to be transmitted" (Knowles et al., 2005, p. 115). If students know the end goal and learn how to interact with the lecturers, a reason arises for doing what may otherwise be perceived as a seemingly meaningless task. This could provide motivation to undertake repetitious practising, or encouragement for students to work through confusion and continue "doing" the mathematics study required. Finally, helping a student evaluate their circumstances and reflect on how they might have changed their mindset, as well as discussing their progress through the learning journey and whether they succeeded in what they planned to do, equates to them engaging in an adult learning experience. Adult students can be metacognitively aware, assisting them in being open to and actively involved in determining their own learning pathways, developing competence and empowerment to learn.

Central to supporting students to be self-directed in mathematics education is tailoring. The students in this study required STEPS teachers to tailor their teaching to suit the individual learning needs of each student. Tailoring is key to ensuring that each student understands the relevance of mathematics content, enhancing their motivation to learn, and helping them gain an understanding of how new mathematical knowledge can be applied to both their current and future lives. Also, of significance in this study is the important role that an understanding of one's individual learning preferences can play in 'making sense' of new knowledge and debunking previous negative notions of self as a mathematics learner. It is only through a thorough understanding of adult learning principles that teachers can do this in a way that truly benefits adult students.

\section{Conclusion}

This article used grounded theory methodology to discover more about how andragogical principles applied in the mathematics units in an enabling course facilitated students in becoming more self-directed learners. It was found that students did demonstrate evidence of how their state of mind, planning, doing and evaluating of their learning were integral to their selfdirected learning. Furthermore, the notion of tailoring by the lecturer in the classroom was found to be significant in helping the students understand and "take it in" so that their mathematics learning was most effective. The significance of this study is its exposition of the importance of tailoring: taking into consideration the needs and skills of the learner, their previous mathematical experiences, their learning style preferences and their motivation in the learning environment. Further study in this area would be of benefit, particularly considering the current problematic trends in mathematical literacies and the field of mathematics education in Australia. 


\section{References}

Australian Qualifications Framework (2013). Australian Qualifications Framework. http://www.aqf.edu.au/aqf/in-detail/aqflevels/

Bunn, R., \& Westrenius, A. (2017). Enabling and changing lives: Stakeholders who affect and are affected by the enabling initiative. International Studies in Widening Participation, 4(1), 55-73. https://novaojs.newcastle.edu.au/ceehe/index.php/iswp/article/view/47

Candy, P. C. (1991). Self-direction for lifelong learning: a comprehensive guide to theory and practice. Jossey-Bass.

Charmaz, K. (2014). Constructing grounded theory (2nd ed.). SAGE.

CQUniversity. (2018). Student Handbook. http://handbook.cqu.edu.au

Duffy, C., \& Wylie, B. (2019, December 3). Australian students behind in maths, reading and science, PISA education study shows. ABC News https://www.abc.net.au/news/2019-12-03/australia-education-results-maths-reading-science-gettingworse $/ 11760880$

Frith, V. (2011). Quantitative literacy provision in the first year of medical studies. South African Journal of Higher Education, 25(4), 725-740.

Heng, M., \& Sudarshan, A. (2013). 'Bigger number means you plus!'-Teachers learning to use clinical interviews to understand students' mathematical thinking. Educational Studies in Mathematics, 83(3), 471-485. doi:10.1007/s10649013-9469-3

Hoffman, B. (2010). "I think I can, but I'm afraid to try": The role of self-efficacy beliefs and mathematics anxiety in mathematics problem-solving efficiency. Learning and Individual Differences, 20(3), 276-283.

https://psycnet.apa.org/doi/10.1016/j.lindif.2010.02.001

Holden, H. (2018). Preparation Skills for University Unit Profile. https://mycourses.cqu.edu.au/pub/profiles/index? unitCode $=$ SKIL $40025 \&$ studyPeriodCode $=H T 1 \&$ year $=2018$

Hughes-Warrington, M. (2013, December 10). Black dog the sum of our anxieties. The Australian.

Jansen, B. R. J., Louwerse, J., Straatemeier, M., Van der Ven, S. H. G., Klinkenberg, S., \& Van der Maas, H. L. J. (2013). The influence of experiencing success in math on math anxiety, perceived math competence, and math performance. Learning and Individual Differences, 24(0), 190-197. https://psycnet.apa.org/doi/10.1016/j.lindif.2012.12.014

Kargar, M., Tarmizi, R. A., \& Bayat, S. (2010). Relationship between Mathematical Thinking, Mathematics Anxiety and Mathematics Attitudes among University Students. Procedia - Social and Behavioral Sciences, 8(0), 537-542. https://doi.org/10.1016/j.sbspro.2010.12.074

Knowles, M. S. (1981). The modern practice of adult education: from pedagogy to andragogy (Revised ed.). Cambridge Adult Education Co. Follett Pub. Co.

Knowles, M. S., Holton, E. F., \& Swanson, R. A. (2005). The adult learner: the definitive classic in adult education and human resource development (6th ed.). Elsevier.

Mather, J. (2014, June 6). Math teachers not qualified. The Australian Financial Review.

McNeilage, A. (2014, February 14). 'Time to act' over HSC students' weak maths. The Sydney Morning Herald

Miflin, B. (2004). Adult learning, self-directed learning and problem-based learning: Deconstructing the connections. Teaching in Higher Education, 9(1), 43-53. https://doi.org/10.1080/1356251032000155821

Morse, J. M. (2010). Sampling in grounded theory. In A. Bryant \& K. Charmaz (Eds.), The SAGE handbook of grounded theory (pp. 229-244). SAGE Publications.

Núñez-Peña, M. I., Suárez-Pellicioni, M., \& Bono, R. (2013). Effects of math anxiety on student success in higher education. International Journal of Educational Research, 58, 36-43. https://doi.org/10.1016/j.ijer.2012.12.004

Pintrich, P. R. (1999). The role of motivation in promoting and sustaining self-regulated learning. International Journal of Educational Research, 31(6), 459-470. https://doi.org/10.1016/S0883-0355(99)00015-4

Pitman, T., \& Trinidad, S. (2016). Pathways to higher education: The efficacy of enabling and sub-bachelor pathways for disadvantaged students. National Centre for Student Equity in Higher Education (NCSEHE).

https://www.ncsehe.edu.au/publications/pathways-to-higher-education-the-efficacy-of-enabling-and-sub-bachelorpathways-for-disadvantaged-students/

Seary, K., \& Willans, J. (2004). It's more than just academic essays and rules of mathematics: Travelling the road with heroes on the STEPS journey as they convert the milestones of their learning journey into signposts for their future. Australian Journal of Adult Learning, 44(3), 306-326.

Thomson, S., De Bortoli, L., \& Underwood, C. (2017). PISA 2015: Reporting Australia's results. https://research.acer.edu.au/ozpisa/22/ 
Tough, A. (1967). Learning without a teacher: a study of tasks and assistance during adult self-teaching projects. Ontario Institute for Studies in Education.

Tough, A. (1979). The adult's learning projects: a fresh approach to theory and practice in adult learning (2nd ed.). Ontario Institute for Studies in Education.

Tough, A., \& Knowles, M. S. (1985). Review: Andragogy in action: Applying modern principles of adult learning. The Journal of Higher Education, 56(6), 707. https://doi.org/10.1080/00221546.1985.11778742

Vukovic, R. K., Kieffer, M. J., Bailey, S. P., \& Harari, R. R. (2013). Mathematics anxiety in young children: Concurrent and longitudinal associations with mathematical performance. Contemporary Educational Psychology, 38(1), 1-10. http://dx.doi.org/10.1016/j.cedpsych.2012.09.001

Willians, J., \& Seary, K. (2007). I'm not stupid after all - changing perceptions of self as a tool for transformation. Australian Journal of Adult Learning, 47(3), 422-452. https://www.ajal.net.au/im-not-stupid-after-all-changing-perceptions-of-selfas-a-tool-for-transformation/

Yaratan, H., \& Kasapoğlu, L. (2012). Eighth grade students' attitude, anxiety, and achievement pertaining to mathematics lessons. Procedia - Social and Behavioral Sciences, 46(0), 162-171. https://doi.org/10.1016/j.sbspro.2012.05.087

\section{Please cite this article as:}

Mann, G., \& Willans, J. (2020). "Monkey see, monkey do, that's not going to actually teach you": Becoming a self-directed learner in enabling mathematics units. Student Success, 11(1), 55-65. https://doi.org/10.5204/ssj.v11i1.1462

This article has been peer reviewed and accepted for publication in Student Success. Please see the Editorial Policies under the 'About' section of the Journal website for further information.

Student Success: A journal exploring the experiences of students in tertiary education

(c) (1) This work is licensed under a Creative Commons Attribution 4.0 International Licence. As an open access journal, articles are free to use with proper attribution. ISSN: 2205-0795 